\title{
Un écrivain-reporter dans les confins tchécoslovaques : Ivan Olbracht en Ruthénie subcarpatique (1931-1936)
}

A Reporter and Writer to the Confines of Czechoslovakia: Ivan Olbracht in Subcarpathian Ruthenia (1931-1936)

\section{Marie-Odile Thirouin}

\section{OpenEdition}

Journals

Édition électronique

URL : https://journals.openedition.org/recherchestravaux/3470

DOI : 10.4000/recherchestravaux.3470

ISSN : 1969-6434

Éditeur

UGA Éditions/Université Grenoble Alpes

Édition imprimée

ISBN : 978-2-37747-301-4

ISSN : 0151-1874

Référence électronique

Marie-Odile Thirouin, « Un écrivain-reporter dans les confins tchécoslovaques : Ivan Olbracht en Ruthénie subcarpatique (1931-1936) », Recherches \& Travaux [En ligne], 98 | 2021, mis en ligne le 28 juin 2021, consulté le 09 août 2021. URL : http://journals.openedition.org/recherchestravaux/3470 DOI : https://doi.org/10.4000/recherchestravaux.3470

Ce document a été généré automatiquement le 9 août 2021 .

(C) Recherches \& Travaux 


\title{
Un écrivain-reporter dans les confins tchécoslovaques : Ivan Olbracht en Ruthénie subcarpatique (1931-1936)
}

\author{
A Reporter and Writer to the Confines of Czechoslovakia: Ivan Olbracht in \\ Subcarpathian Ruthenia (1931-1936)
}

Marie-Odile Thirouin

\section{Introduction}

1 En 1931, la Ruthénie subcarpatique est à la mode. Quand il arrive dans la région en juillet de cette même année, Ivan Olbracht n'est pas le premier écrivain-reporter ${ }^{1}$ tchèque à s'y intéresser, ni le dernier ${ }^{2}$ : sans même parler des publications isolées dans la presse, ni des ouvrages scientifiques qui abondent dès le début des années $20^{3}$, on dénombre 31 romans, essais, récits de voyage, recueils de poèmes, nouvelles, contes ou reportages ayant trait à la Ruthénie et parus en tchèque entre 1926 et 1939, dont certains de la plume d'écrivains renommés comme Karel Čapek, Vladislav Vančura ou Jaroslav Durych ${ }^{4}$. Olbracht n'est donc pas une exception: il semble obéir à un engouement né en 1919 avec le rattachement inattendu de la Ruthénie au tout nouvel État tchécoslovaque, entériné par les traités de Saint-Germain et de Trianon. Pourtant, c'est le nom d'olbracht qui, rétrospectivement, reste attaché à cette région: les trois œuvres qu'il lui a consacrées - un recueil de reportages, un roman et une trilogie de nouvelles, écrits et publiés entre 1931 et $1937^{5}$ - constituent d'une part le sommet de son œuvre (à ce titre, elles font partie du canon de la littérature de langue tchèque); d'autre part, Olbracht appartient encore à la mémoire culturelle de la Ruthénie, aujourd'hui ukrainienne ${ }^{6}$ : à Koločava [КОлочАВА], village où il a longuement séjourné dans les années 30 , un petit musée lui est consacré dans l'ancienne école tchèque, et son buste orne les parages de la nouvelle école de l'époque soviétique ${ }^{7}$. Cette situation 
singulière pose plusieurs questions: qu'est-ce qui distingue la démarche d'Ivan Olbracht de celle de ses confrères? De quoi ses reportages traitent-ils? Et enfin, quel est leur rapport avec l'œuvre de fiction qu'il écrit parallèlement?

\section{La Ruthénie subcarpatique ou l'«Orient tchécoslovaque »}

2 À l'issue de la Première Guerre mondiale, les Tchèques obtiennent la création d'un État indépendant qui englobe la Slovaquie et la Ruthénie subcarpatique, deux régions ayant appartenu au royaume de Hongrie et, de ce fait, dotées d'une histoire très différente de celle des pays tchèques historiques (Bohême, Moravie, Silésie). La Tchécoslovaquie constitue donc « un État singulièrement inhomogène, très largement dominé par ses composantes tchèques sur le plan politique, économique, social et culturel ${ }^{8} "$, comme sur le plan démographique. Gertraude Zand fait toutefois remarquer une différence importante entre la Slovaquie et la Ruthénie: si la première a eu par le passé des relations intenses avec les pays tchèques, les relations avec la seconde ont été pratiquement inexistantes avant 1918 ; elles ont cessé d'ailleurs tout aussi brutalement en 1939, après l'occupation de la Ruthénie par la Hongrie, puis son occupation et enfin son annexion par l'Union soviétique 9 aux termes d'un accord signé en juin 1945, en l'absence de tout représentant de la Ruthénie ${ }^{10}$.

3 Les dirigeants tchèques en exil pendant la Première Guerre mondiale n'avaient donc pas songé à réunir la Ruthénie et la Tchécoslovaquie avant 1918, date à laquelle ils acceptèrent le rattachement à leur État d'un pays surtout peuplé de Ruthènes, un peuple slave «frère » réputé inapte à l'indépendance ${ }^{11}$. De fait, pour les Ruthènes, la guerre en cours à l'Est rendait peu séduisante la perspective d'une réunion tant avec l'Empire russe en décomposition qu'avec une Ukraine indépendante fragile ${ }^{12}$. Quant à la Hongrie, ses prétentions sur la Ruthénie étaient inaudibles, car la Hongrie faisait partie des vaincus et était d'autant plus indésirable dans la région que les Alliés souhaitaient disposer d'une frontière avec la Roumanie en intégrant la Ruthénie à la Tchécoslovaquie amie. Ce fut donc la solution encouragée par les États-Unis et adoptée par la délégation ruthène, menée par Grigorij Žatkovič, qui signa en octobre 1918 à Philadelphie un accord avec le futur président tchécoslovaque, Tomáš Garrigue Masaryk, en échange d'une promesse de large autonomie ${ }^{13}$.

Le rattachement de la Ruthénie subcarpatique à la Tchécoslovaquie sous le nom de Podkarpatská Rus, effectif au début de l'année 1920, n'était pourtant pas du goût de tous les Tchèques, si l'on en croit les journaux de l'époque. La Ruthénie y est qualifiée de « cheval de Troie » (danajskýdar), c'est-à-dire de cadeau empoisonné, ou encore de «boîte de Pandore» (Pandořina skřiňka) d'où le malheur allait s'abattre sur la Tchécoslovaquie entière ; ou dans un autre registre, on la considère comme le début de l'Asie, censée commencer au-delà de la ville de Košice en Slovaquie (Asie za Košicemi ${ }^{14}$ ), dernier rempart contre cette terre barbare où doivent "s'exiler» jusqu'à 20000 fonctionnaires tchèques (et slovaques pour une faible part) dès le début des années $20^{15}$. De quoi les Tchèques ont-ils si peur? C'est que, sur ce territoire au relief accidenté et inhospitalier, qui fait un peu plus de $10 \%$ de la superficie de la Tchécoslovaquie de l'époque, on compte en 1919 environ 600000 habitants (soit 4,5\% de la population tchécoslovaque) vivant pour la plupart dans le plus grand dénuement. Plus de $60 \%$ sont des Ruthènes, qui appartiennent à trois ethnies distinctes, Lemkos, 
Boykos et Houtsoules, mais on trouve aussi là plus de 100000 Hongrois, 80000 Juifs (soit autant que les Juifs des pays tchèques historiques), des Allemands (environ 10000 ), des Roumains, quelques Polonais, Slovaques et Tchèques. $90 \%$ de la population de Ruthénie est employée au travail de la terre. Le taux d'analphabétisme y est de $43 \%$ en moyenne, mais atteint $98 \%$ dans les zones les plus reculées ${ }^{16}$. Les Juifs de Ruthénie, précisons-le, arrivés de Galicie au XVII siècle ou tout récemment encore pour fuir les zones de combats à l'Est, sont pour la plupart des Juifs hassidiques, c'est-à-dire de ces Juifs orientaux yiddishophones que les Juifs assimilés des grandes métropoles de l'Ouest de l'Europe regardent avec mépris ou inquiétude - pensons au trouble de Kafka découvrant en 1911 le yiddish à l'occasion de la tournée pragoise d'une troupe de théâtre venue de Galicie ${ }^{17}$.

5 Le journaliste Vojtěch Lev (1882-1974) est l'un des premiers à se rendre de Prague en Ruthénie pendant l'été 1920, pour le compte du journal Právolidu [Droit du peuple], organe du Parti social-démocrate tchécoslovaque. Dans un ensemble de reportages paru à l'automne 1920 sous le titre Brána na východ. Karpatská Rus [Une Porte vers l'Est : la Ruthénie carpatique], il fait le portrait d'" une terre malheureuse", "le monstre de l'Europe ", " moitié Orient, moitié Russie », un « bout d'Europe où le malheur [a pris ses quartiers] et où le crime [est] chez lui ${ }^{18} »$. Les responsables de cette situation, selon lui, ce sont surtout les Hongrois qui, au cours de leur domination séculaire sur la Ruthénie, l'auraient transformée en un véritable " morceau de l'Afrique la plus ténébreuse » (kus nejtemnějš́ Afriky $^{19}$ ). Cette référence surprenante à l'Afrique n'est pas l'apanage de Lev : on la rencontre assez souvent dans la presse et le discours politique de l'époque ${ }^{20}$, à côté de la référence plus attendue à l'Orient qui, dans les années 30 , sert même d'argument pour attirer les touristes tchèques en Ruthénie ${ }^{21}$. Sous la plume de Lev, la référence à l'Afrique est le moyen d'installer la Ruthénie dans une relation de type colonial avec Prague, sur le modèle des "grandes" nations européennes et de leurs colonies africaines: elle véhicule toute une série de stéréotypes liés à l'imaginaire colonial, dont celui de la ténèbre (temno), qui renvoie métaphoriquement à l'état d'enfance - ou d'arriération - dans lequel serait plongé le peuple ruthène. Plus profondément, ce motif de la ténèbre entre en résonance quasiment affective avec le mythe national tchèque, puisque c'est le nom qu'Alois Jirásek donne en 1915, dans son roman historique «à la Walter Scott » intitulé précisément Temno, à ce qu'il considère comme une longue éclipse nationale après la Bataille de la Montagne Blanche : pour Lev, les Tchèques enfin sortis de leur assujettissement séculaire, sont maintenant en position de prendre en charge l'émancipation d'un peuple frère.

6 C'est pourquoi ils ont le sentiment d'un devoir, celui de s'atteler à un véritable travail de civilisation dans ces terres désolées dont ils prennent en main l'administration, le système scolaire, le système de santé, les transports, etc., en s'y sentant pourtant toujours étrangers. Ils entretiennent par conséquent un rapport ambivalent avec ces confins, territoire à la fois dedans et dehors, proche et lointain, «lié à la vocation impériale» d'un centre à la fois paternaliste (il se dote d'«une mission institutionnelle » dans cette région archaïque dépourvue d'infrastructures modernes) et nostalgique (il y projette ses fantasmes d'authenticité et de ressourcement auprès d'un peuple frère encore " jeune »), pour reprendre les termes que Delphine Bechtel et Xavier Galmiche appliquent de façon générique à ces lieux de confusion «à la frontière » de l'Europe centrale ${ }^{22}$. C'est ce "monde sombre et malheureux », comme ils l'écrivent encore, objet de "fascination » autant que de "répulsion », que Vojtěch Lev, dans l'intérêt de la Tchécoslovaquie, voudrait voir tirer de la misère économique et 
culturelle pour en faire une sorte de sas, de "pont doré » $\left(\right.$ zlatý most $\left.^{23}\right)$ vers le monde russe - car «c'est notre porte à nous vers l'Est ${ }^{24}$ !» Le propos est ouvertement impérialiste.

\section{Ivan Olbracht, reporter en Ruthénie subcarpatique (1931-1936)}

7 Ivan Olbracht, onze ans plus tard, prend l'exact contrepied du discours de Vojtěch Lev, au point de devenir en quelques mois le ténor du discours adverse, "antiimpérialiste ", sur la Ruthénie. Pourtant, Olbracht appartient à la même sensibilité politique que Lev et publie dans les mêmes journaux que lui. Comment expliquer ce décalage ? C'est d'abord que le temps a passé : non seulement l'autonomie promise par l'accord de Philadelphie n'a pas été accordée à la Ruthénie, mais «les Ruthènes se plaignent de la corruption et des vols commis par des fonctionnaires tchèques, en particulier ceux qui travaillent à la campagne, et les rapports du gouvernement tchèque confirment que beaucoup de fonctionnaires ont essayé de tirer profit de leurs diverses positions ${ }^{25}$ ». La Ruthénie n'est donc plus cet « objet muet de la colonisation tchèque $^{26}$ » qu'elle était encore au début des années 20 . Olbracht a certainement entendu ces plaintes ${ }^{27}$, lui qui par le passé a été en contact avec des Ruthènes, d'abord pendant son service militaire dans l'armée austro-hongroise (il a écrit en 1910 une nouvelle sur un soldat ruthène du nom de Chomjak, comme on en croise chez Jaroslav Hašek ou Józef Wittlin ${ }^{28}$ ), puis à Vienne, où il a été responsable de la rubrique culturelle du journal social-démocrate de langue tchèque Dělnické noviny [Le Journal ouvrier] de 1909 à $1916^{29}$.

8 Pourtant, cet intérêt ancien ne suffit pas à expliquer son engagement des années 30 en faveur de la Ruthénie. Que vient-il faire dans ces parages, à près de 50 ans, alors qu'il n'a pas là d'attaches personnelles ni professionnelles? De fait, ce journaliste expérimenté (à partir de 1906, il a toujours travaillé pour la presse de gauche, à Vienne ou à Prague, en particulier entre 1916 et 1920 pour Právo lidu [Le Droit du peuple], puis pour Rudé právo [Le Droit rouge], fondé en septembre 1920 par des journalistes dissidents de Právo lidu et futur organe du Parti communiste tchécoslovaque ${ }^{30}$ ), est à un tournant de son existence. C'est un homme engagé qui a adhéré au Parti communiste dès sa fondation en mai 1921, de retour d'un séjour de neuf mois en Russie soviétique dont il a rapporté une série de reportages publiés en trois volumes sous le titre d'Obrazy ze soudobého Ruska [Tableaux de la Russie contemporaine] en 1920-1921. Cet engagement radical lui vaut d'ailleurs deux courts séjours en prison en 1926 et 1928, à Ostrava et à Prague, dont il tire en 1930 une sorte de reportage romancé, Zamřižované zrcadlo [Un miroir avec des barreaux ${ }^{31}$. C'est dans cette période d'intense activité politique, en 1925-1926, qu'il publie en feuilleton un roman appelé à une large diffusion dans la Tchécoslovaquie communiste d'après-guerre, Anna proletárka [Anna la prolétaire] : Anna est une jeune fille de la campagne, venue en 1920 chercher du travail à Prague, dont la passivité naïve des débuts se transforme en un engagement communiste militant ${ }^{32}$. Or en février 1929, Olbracht est le principal initiateur d'un texte connu dans l'histoire littéraire tchèque sous le nom de Manifest sedmi [Manifeste des sept], intitulé "Des écrivains communistes s'adressent aux ouvriers communistes " (Spisovatelé komunisté komunistým dělníkům) : ce texte, publié sous forme de tract, proteste contre la prise en main du Parti communiste tchécoslovaque, à l'issue de son $V^{e}$ Congrès, par Klement 
Gottwald et sa « clique $^{33}$ ». Olbracht est exclu du Parti communiste un mois plus tard, en mars 1929, et se retrouve brutalement sans emploi, privé de son poste de rédacteur en chef à Rudé právo et de l'appui de tout l'appareil communiste, de ses réseaux et de ses médias.

9 En réalité, Olbracht est par là libéré d'un travail de propagande pesant et d'une pratique quotidienne du journalisme lourde de contraintes ${ }^{34}$. Il décide alors de se tourner vers l'écriture littéraire qu'il a jusqu'alors subordonnée à son engagement politique, du moins depuis $1918^{35}$. C'est dans ce contexte qu'il arrive en juin 1931 dans l'Est de la Slovaquie, à la recherche de l'inspiration qu'il attend toujours des pauvres, des marginaux, des réalités sociales concrètes, mais dans un cadre privé à présent. À Krasný Brod, dans le district de Medzilaborce à la frontière avec la Pologne, il rencontre un groupe d'émigrés ruthènes : c'est cette circonstance, semble-t-il, qui le décide à se rendre en juillet à Užhorod, la « capitale » de la Ruthénie, où résident deux familles amies qu'Olbracht a connues à Vienne. Celles-ci l'envoient à leur tour à Volové (aujourd'hui мІжГІР'я [Mizshirja]) chez un avocat qui l'encourage à se rendre dans le village de Koločava, à la recherche d'informations sur la vie de Mykola Sjuhaj (миколА ПЕТРОВИЧ СЮГАЙ), un déserteur et brigand ruthène abattu dix ans plus tôt dans cette région de la Verchovina (ВеРХовИнА), les hautes terres ${ }^{36}$. À partir de cette date, et pendant six années consécutives, plusieurs mois par an, été comme hiver, Olbracht sillonne la Ruthénie, surtout à pied. Il voit les centres urbains (Užhorod, Mukačevo, Chust), mais c'est le monde rural qui l'attire, les montagnes, et en particulier la région de Koločava, son port d'attache, où il s'installe pour écrire, mais aussi prendre part à l'instruction des enfants à l'école du village ou, à l'occasion, servir d'écrivain public dans cette région où sévit l'analphabétisme ${ }^{37}$.

\section{Les reportages (1931-1935)}

Son projet initial, celui de rechercher des informations sur Mykola Sjuhaj pour un ouvrage de fiction, évolue au contact du pays: Olbracht décide d'écrire et de publier d'abord des reportages. Voici comment il justifie son choix rétrospectivement, en 1935 :

Je suis venu ici écrire de la littérature. Mais quand j'ai vu dans quelle misère immense on précipitait ce pays, quels dégâts culturels et politiques sont provoqués ici sciemment et dans un but intéressé, comment une bande de gredins bien organisée met impunément à sac tout ce pays, il était impossible, au moins dans un premier temps, de ne pas laisser la littérature de côté et de ne pas écrire sur ces problèmes. Mes articles ont suscité un grand émoi. En particulier pour décider de ce que je sais ou de ce que je ne sais pas. Des choses, j'en ai su beaucoup, mais je n'en ai écrit qu'une petite partie, puisque la vérité reste certes la vérité, mais pour qu'elle devienne vérité officielle, il est besoin de preuves souvent inaccessibles au simple particulier. Et justement, ce pays oublié où je me suis arrêté, était un véritable eldorado pour les criminels qui le gouvernent. Ici, on volait et on dévalisait dans une paix royale et avec une tranquille évidence. C'était le lieu d'une véritable idylle pour brigands. Et voilà qu'est arrivé une personne pour mettre un terme à tout cela ${ }^{38}$.

Olbracht, attentif aux questions de justice sociale, est passé du projet d'évocation romanesque de la vie du brigand de grand chemin, le hors-la-loi Mykola Sjuhaj, à la dénonciation des brigands qui pillent la Ruthénie sous couvert de la loi, au premier rang desquels figurent les Tchèques. Tandis que Vojtěch Lev écrivait pour les Tchèques une fois de retour à Prague, de l'extérieur de la Ruthénie, Olbracht inverse donc la 
perspective : il écrit de Ruthénie à l'adresse des Tchèques qu'il prend violemment à partie.

Un jeune chercheur de l'Université Komenský de Bratislava, Pál Száz, a analysé le positionnement adopté par Olbracht et a défini sa stratégie en six points ${ }^{39}$ :

1. Le destinataire des reportages étant tchèque, Olbracht choisit la Bohême comme contexte de référence, c'est-à-dire le «centre » connu de ses lecteurs, dont il rapproche la "périphérie » ruthène mal connue qu'il s'agit d'éclairer par comparaison ;

2. Sur le plan rhétorique, la Ruthénie est définie comme l'exact opposé de la Bohême : d'un côté, des montagnes couvertes de forêts impénétrables et hostiles et une population rurale vivant dans la misère; de l'autre, un paysage de paisibles collines depuis longtemps humanisé, dominé par des centres urbains et industriels ;

3. Sur le plan institutionnel, Olbracht publie ses reportages dans des médias marqués à gauche (mais non communistes), visant explicitement un public susceptible d'entendre et de diffuser ses critiques: le Literárnínoviny [Le Journal littéraire], un bi-mensuel dont le rédacteur en chef est à l'époque son ami Josef Hora ${ }^{40}$, et l'éditeur Otto Girgal qui est aussi l'éditeur des amis d'Olbracht récemment exclus du Parti communiste ;

4. Sur le plan du genre littéraire, le choix du reportage se fait explicitement aux dépens du récit de voyage et de sa recherche de pittoresque. Olbracht s'appuie certes sur ses propres observations, mais il les encadre de chiffres et de références qui constituent un écran d'objectivité derrière lequel le «je» s'efface: l'ethos discursif construit est celui de l'ethnographe, non pas du voyageur. Toutefois, les sources précises ne sont pas citées, à l'exception remarquable de deux reportages sur la Ruthénie récemment traduits en tchèque, celui du Français Albert Londres, Le Juif errant est arrivé, et celui du Hongrois Miklós Bártha, Au pays des Khazars: Olbracht les cite non pour s'en réclamer, mais pour dénoncer comme des stéréotypes (et donc des erreurs) ce que Londres écrit de la misère juive et Bártha de l'usure juive ${ }^{41}$.

5. Ses reportages ont un but politique explicite, celui de mettre en cause la politique du gouvernement tchécoslovaque en Ruthénie; ce but est atteint: les reportages d'olbracht déclenchent une véritable bataille, dans la presse et au Parlement, entre « impérialistes » et "anti-impérialistes », eux-mêmes divisés entre le Parti communiste, d'une part, et les écrivains communistes « dissidents » autour d'Olbracht, d'autre part, en ordre dispersé42

6. Cette mise en cause a en outre une épaisseur temporelle, une dimension historique, puisqu'elle repose sur la comparaison de la domination tchèque en Ruthénie avec la domination hongroise antérieure, comparaison favorable aux Hongrois, contrairement aux conclusions de Vojtěch Lev en 1920.

13 L'objectif d'une telle stratégie d'écriture, explique Pál Száz, est de positionner l'Autre (la Ruthénie) de sorte à pouvoir "l'apprivoiser» (domesticate), c'est-à-dire entrer en relation avec lui ${ }^{43}$. C'est en effet la sympathie de l'auteur pour son objet qui frappe à la lecture des reportages ${ }^{44}$ : ce locuteur à la première personne (ou désigné par une périphrase : l'auteur de ces reportages [pisatel těchto reportáži]), intermédiaire entre « ils » (en Ruthénie) et « vous » (à Prague), est parfois amusé, interloqué ou déstabilisé, mais jamais hostile à ce pays, bien au contraire : il n'a ni condescendance ni désir de juger, sinon la politique du "colonisateur» qui, elle, fait l'objet d'une indignation non contenue. Les reportages d'Olbracht paraissent en trois temps, de 1931 à 1935, en s'étoffant d'une version à l'autre ${ }^{45}$ : d'abord dans le Literární noviny [Journal littéraire], entre septembre et novembre 1931, en quatre livraisons divisées en sept parties et publiées sous le titre général de Combat pour la culture en Ruthénie subcarpatique ${ }^{46}$; puis au printemps 1932, paraît chez Otto Girgal un livre de 92 pages sous le titre de Terre 
sans nom. Reportages de Ruthénie subcarpatique ${ }^{47}$; enfin, en avril 1935, est publié chez Melantrich à Prague un livre de 240 pages intitulé Les Montagnes et les siècles. Recueil de reportages de Ruthénie subcarpatique ${ }^{48}$.

Commentons tout d'abord l'évolution du titre. Les articles du Literární noviny sont placés sous le signe du "combat pour la culture", ce qui est une façon de rappeler aux Tchèques leur propre émancipation nationale par la culture au $\mathrm{XIX}^{\mathrm{e}}$ siècle, et donc de les déloger du rôle confortable de civilisateur dont ils se sont dotés en Ruthénie. Ensuite, le lieu d'où parle Olbracht est la Ruthénie elle-même ${ }^{49}$, comme le choix de la préposition $(-z)$ marquant l'origine dans les deux titres suivants y insiste encore. Le titre combatif des articles disparaît pourtant de la couverture du premier livre, Terre sans nom, mais devient, sous une forme légèrement différente, le titre du quatrième et dernier chapitre de ce livre : «Boj o kulturu a jazyk » [ "Combat pour la culture et la langue »] - l'adjonction de la dimension linguistique est symboliquement importante : les Ruthènes ne sont pas des sauvages privés de moyen d'expression, mais un peuple que ses souverains successifs ont privé de sa langue. C'est ce que veut signifier le titre du livre, Terre sans nom, tiré des premières phrases de ce même chapitre sur la langue : "Cette terre est encore privée de nom. Ou pour mieux dire, elle en a trop pour en posséder un ${ }^{50}$. » Et Olbracht d'énumérer tous les noms " politiques », dit-il, donnés de l'extérieur à cette région par ceux qui ont jusqu'à présent décidé unilatéralement de son sort (Hongrois, Tchèques, Russes, Ukrainiens, conférences internationales ${ }^{51} \ldots$..), avant de se demander comment se désignent elles-mêmes les "ethnies [kmeny] qui vivent ici » et de constater qu'elles "n'ont pas encore de nom en commun », car «le peuple [lid] de Subcarpatie n'est pas encore une nation [národ]», il n'est encore qu' " une masse ethnographique " inconsciente d'elle-même ${ }^{52}$. Olbracht insiste sur le caractère provisoire de cette situation : comme le peuple tchèque, le peuple ruthène se dotera lui-même d'un nom le jour où il sera devenu une nation, ce qui ne peut manquer de se produire.

15 La mise en garde contenue dans le titre Terre sans nom disparait avec le titre du second livre, Les Montagnes et les siècles, moins politique et plus poétique ${ }^{53}$. C'est peut-être la marque qu'en 1935, le succès des premiers reportages a déjà obtenu à Prague la prise de conscience souhaitée, comme le constate dès 1932 un autre ami d'olbracht, František Xaver Šalda, commentant ses reportages :

Nous n'avons pas de colonies outre-mer [...]. En échange, nous avons la Ruthénie subcarpatique, sorte d'appendice oriental brumeux de notre République au-delà de la Slovaquie, région à propos de laquelle nul n'avait d'idées très précises avant la guerre. Et ce petit bout de terre, habité par le misérable peuple ruthène, est devenu après la guerre mondiale le premier terrain d'expérimentation des capacités colonisatrices du bourgeois tchèque. Mais voilà que tout cela a pris un tour lamentable. Avant la guerre, c'était les Hongrois qui avaient colonisé la Ruthénie subcarpatique, et comme le montre Ivan Olbracht, ils l'avaient colonisée avec plus d'humanité, de raison et d'intelligence. La colonisation tchèque, elle, a versé dans la tradition colonisatrice de toutes les grandes nations culturelles de l'Europe de l'Ouest : au bout du compte, on en est arrivé à faire de la carabine du gendarme le vecteur culturel le plus sûr ${ }^{54}$.

Le titre choisi par Olbracht en 1935 définit en tout cas la Ruthénie comme un espacetemps placé par métonymie sous le signe des montagnes (le pluriel donne une épaisseur concrète au paysage), ces montagnes correspondant à autant de strates de temps juxtaposées, non pas superposées ${ }^{55}$ : quand on les parcourt, on passe du Moyen Âge (le temps où vivent encore les Ruthènes) au xvIII siècle (le temps des 
Allemands du Tyrol venus s'installer en Ruthénie à cette date) et aux temps bibliques et rabbiniques qui sont ceux où vivent les Juifs hassidiques (pour eux, toute contingence historique ne prend sens qu'en fonction du texte biblique, trace de la rencontre entre Dieu et son peuple). Olbracht ne hiérarchise pas ces temps différents qui ont chacun leur logique et leur raison d'être, mais il fait de ce voisinage curieux, tantôt harmonieux, tantôt conflictuel, la marque spécifique d'un pays où l'espace est en réalité du temps matérialisé.

Examinons ensuite la structure des reportages. Le livre de 1932 reprend le texte des articles de 1931, mais le développe et le redistribue en quatre chapitres qui figurent ensuite tels quels dans la version de 1935, dans l'ordre qui suit: "Un village du $\mathrm{XI}^{\mathrm{e}}$ siècle ", "Ceux dont on n'avait pas entendu parler avant » (les Tchèques!), "Les Juifs » et «Terre sans nom » («Combat pour la culture et la langue » dans la version de 1932). Tous sont datés de 1932, sauf le quatrième, daté de 1931, alors qu'il correspond bien à la fin des reportages publiés dans Literární noviny et qu'il est lui aussi retouché - peut-être parce que c'est le premier dans l'ordre d'écriture ou la matrice aux yeux d'olbracht? La version de 1935 adjoint à ces quatre chapitres six nouveaux chapitres, tous datés de 1934 : «Les brigands ", "Le XVIII e siècle ", "Une négociation difficile avec Anća Burkalová ", "La mandra " (c'est le nom local d'une eau-de-vie dénaturée, coupée de café, de caramel et d'eau), «De la puissance du désir » (deux recettes de sorcière pour envoûter les cœurs rétifs) et «Cette terre se nationalise ${ }^{56}$ ».

L'organisation de cette matière de plus en plus ample obéit à quelques principes généraux définissant la poétique d'olbracht, qui est une poétique du dévoilement :

1. L'attention du reporter tchèque va aux hommes, aux habitants de cette contrée, à leur culture plus qu'à la nature qui n'en est que le cadre, et parmi eux, ce sont les Ruthènes et les Juifs auxquels il consacre le plus de pages, entrant dans le détail de leurs modes de vie concrets, riches d'une culture ancienne parfaitement adaptée à la rudesse du milieu (habitat, habillement, alimentation, activités économiques, croyances, rites et coutumes, art, légendes et chansons...). Olbracht montre par contraste les effets désastreux de l'irruption d'une modernité agressive et inadaptée dans une société et une culture fragiles.

2. La préoccupation dominante est donc une préoccupation documentaire, informative: dans ce but, Olbracht varie la profondeur de champ, passant du plan général à des anecdotes personnelles significatives (comme son intervention dans l'affaire qui oppose Anća Burkalová à l'État tchécoslovaque) ou à des faits curieux (le goût des Ruthènes pour la sorcellerie, les croyances cosmologiques des Juifs...), pour changer le regard des Tchèques sur la Ruthénie, mais sans en faire le lieu d'une idylle mensongère.

3. La misère, la crasse, l'alcoolisme, l'arriération, la superstition, etc., sont néanmoins rapportés à leur véritable cause socio-économique, la succession de «maitres » impitoyables dont les Tchèques sont les derniers et les pires: Olbracht apostrophe ses compatriotes avec vigueur, leur pose des questions brutales, ironise sur leur aveuglement, s'indigne de leur cupidité, sans toutefois s'exonérer entièrement de leurs crimes, car il les rejoint parfois dans un « nous » où il s'englobe lui-même ${ }^{57}$.

\section{Du reportage à la fiction (1933-1937)}

Au même moment, la transition vers la fiction se fait en douceur et en léger décalage par rapport aux reportages, considérés comme prioritaires par Olbracht, on l'a vu. Mais ces reportages préparent manifestement l'écriture romanesque, et inversement, l'œuvre de fiction peut être considérée comme l'aboutissement des reportages d'où elle 
tire sa «chair » : la frontière entre les deux genres n'est pas étanche ${ }^{58}$. Il existe d'ailleurs entre eux un intermédiaire, le cinéma: Olbracht écrit avec Karel Nový le scénario d'un film, Marijka nevěrnice [Marijka l'infidèle], tourné à Koločava en 1933 par Vladislav Vančura avec des acteurs non professionnels - c'est-à-dire les habitants du lieu - en trois langues, tchèque, ruthène, yiddish (Olbracht y joue un petit rôle ingrat et significatif, celui du touriste tchèque en quête d'alcool et de cigarettes ${ }^{59}$ ). La première du film a lieu à Prague en 1934, et il est ensuite diffusé en Amérique du Nord sous le titre de Forgotten Land. C'est donc un film militant, mais qui agence les informations sur la misère de ces contrées et l'exploitation dont elles font l'objet, d'après une trame fictive, l'adultère de Marijka finalement pardonné par son mari Petro. Cette trame n'est pas aussi anecdotique qu'il y paraît, car l'adultère a des raisons profondes : c'est pour Marijka une part de rêve, le moyen d'échapper à un quotidien sordide et injuste, voué à l'indigence matérielle et morale. L'issue est moins heureuse qu'on pourrait le croire, dans la mesure où il n'y a pas de réelle possibilité d'évasion pour Marijka, prisonnière du village. La transition est faite vers le roman qui greffe cette fois la fiction sur un personnage historique.

Nikola Suhaj le brigand, écrit juste après le scénario du film, paraît en $1933^{60}$, un an après la publication de Terre sans nom. Le lieu de l'action est encore une fois Koločava, là où Olbracht a mené l'enquête sur la figure historique de Mykola Sjuhaj (1898-192161). Pourtant, l'ambition du roman n'est pas de reconstituer les faits, mais de montrer au contraire comment Sjuhaj est devenu le noyau d'une légende, en cristallisant autour de lui rumeurs et récits : c'est la raison pour laquelle le roman commence et se termine par une scène où le narrateur écoute ce que les bergers racontent du brigand, sur leur terrain à eux, dans la montagne, de nuit ${ }^{62}$. Le personnage qu'Olbracht tire de ces récits, correspond à la «forme simple » de la légende (legenda, ce qui doit être lu) décrite par André Jolles $^{63}$ : c'est une figure historique devenue exemplaire, en l'occurrence l'incarnation de l'immortelle aspiration du peuple ruthène à la justice sociale; Šuhaj s'inscrit de la sorte dans la lignée des brigands au grand cœur, volant aux riches pour donner aux pauvres, comme avant lui, dans ce pays, Oleksa Dovbuš (ou Dovboš) ; il est dessiné à travers une poignée de motifs récurrents - son invulnérabilité supposée, sa démarche longue et souple, la formule d'auto-identification qu'il utilise toujours pour se présenter à ses victimes ("Je suis Nikola Šuhaj»), la mort par trahison; enfin, dans le roman, il a un contre-modèle, en l'occurrence le gendarme tchèque Svozil, son rival auprès de la belle Eržika, partagée entre son attirance pour le brigand de légende et la promesse d'une vie paisible et bourgeoise incarnée par Svozil, l'anti-légende.

21 Le roman d'olbracht a connu d'emblée un immense succès, mais il a aussi suscité de violentes critiques : on lui a reproché de mettre histoire et fiction sur le même plan, de transformer un bandit en héros et de ridiculiser la gendarmerie tchèque ${ }^{64}$ ! Son livre a même été retiré des écoles, et la traduction ukrainienne en a été confisquée ${ }^{65}$. Olbracht a répliqué à ces critiques, en particulier dans le chapitre consacré aux brigands dans son recueil de reportages de 1935, Les Montagnes et les siècles:

Nikola Šuhaj n'a pas été un grand brigand au sens social ou politique du terme. Mais il a rempli une autre mission des brigands, véritablement la plus belle des missions, qui l'a placé dans le voisinage immédiat des plus grands brigands, et même d'Oleksa Dovboš : il a fécondé l'imagination du peuple. / C'est l'âme du peuple ruthène, aspirant à ce qu'on lui rende droit et à ce qu'on lui fasse justice, qui a fait de Nikola Šuhaj un grand brigand et un personnage tragique, le dotant de forces et de pouvoirs que ce peuple lui-même n'a pas, mais désire ardemment posséder ${ }^{66}$. 
22 juif qui, lui, n'est pas porteur de légendes, mais d'un mythe. André Jolles voit dans le mythe une autre de ces "formes simples" antérieures aux textes littéraires, mais actualisées par elles : pour lui, le mythe fournit un schéma explicatif, il répond sous forme de récit imagé à une question sur les causes des événements qui se produisent dans le monde, et sa fonction est à la fois étiologique et allégorique ${ }^{67}$. La réflexion d'Olbracht sur le mythe, outre sa rencontre avec les Juifs hassidiques, est nourrie par un travail alimentaire de traduction qu'il effectue au moment où il remodèle ses premiers reportages en vue d'une publication étoffée : entre 1934 et 1937 en effet, il traduit en tchèque les trois premiers volumes de la tétralogie de Thomas Mann, Joseph und seine Brüder [Joseph et ses frères], parus entre 1933 et $1937^{68}$. Or, comme l'explique Olga Zitová dans son ouvrage consacré à l'influence de Mann sur Olbracht, grâce à la référence au Dieu d'Abraham, d'Isaac et de Jacob en dehors de l'histoire, le Joseph de Thomas Mann sait qui il est. Car dans sa situation historique, il reconnaît un schéma mythique dans lequel un "rôle » - celui de nourricier du peuple juif - lui est attribué et s'actualise dans sa vie. Et pourtant, son «je » émerge du schéma mythique identifié dont il ne reste pas prisonnier : au contraire, Joseph s'en émancipe pour façonner sa propre identité, conscient qu'il se soumet ainsi à la volonté du Dieu qu'il veut servir ${ }^{69}$. Après son roman sur Šuhaj, Olbracht s'interroge donc sur la question de l'articulation entre identité historique et identité mythique cette fois, identité collective et identité personnelle, mais du point de vue des Juifs de Ruthénie, dotés - au contraire des Ruthènes - d'une identité mythique forte: les Ruthènes, en attente d'une identité historique, se situent collectivement en deçà de l'histoire dont l'entrée leur est refusée (ils sont refoulés dans la légende), tandis que les Juifs refusent d'y entrer pour préserver leur identité de peuple de Dieu au-delà de l'histoire.

La trilogie de récits qu'Olbracht leur consacre s'intitule Le Golet dans la vallée et est parue en $1937^{70}$. Le golet en yiddish (ou galuten hébreu) désigne la situation d'exil [גלות] des Juifs au milieu des nations. La vallée dont il est ici question est celle où se trouve le village de Polana ou Polyana (полянА), dans le district de Volové, peuplé de Juifs hassidiques, mais cette vallée est aussi la vallée de larmes qu'est ce monde, selon la tradition biblique. Olbracht a réuni dans ce livre trois nouvelles écrites lors de son dernier séjour en Ruthénie, entre juin et août 1936: "Youltcha et le miracle", "Incident au mikvé " (le bain rituel) et "Les yeux tristes d'Hana Karadjitch"1 ». On retrouve les mêmes personnages d'une histoire à l'autre, mais chacune d'elles est racontée du point de vue d'un personnage différent : le journalier Bajnyš Zisovič, puis le tailleur Pinches Jakubovič et enfin la fille du kremer Josef Šafar, Hana Šafarová (Hanele en yiddish). À travers eux, Olbracht montre comment le monde traditionnel des Juifs hassidiques de Ruthénie s'accommode du temps historique. Cette situation est déclinée dans deux registres ${ }^{72}$, selon que les personnages parviennent ou non à maîtriser cette confrontation: le registre comique, quand le personnage se tire d'affaire à l'aide du schéma mythique (l'histoire de Bajnyš Zisovič est une version dérisoire du sacrifice d'Abraham, et celle de Pinches Jakubovič la transposition 
prosaïque et triviale de l'épisode biblique où Josué arrête la course du soleil, le temps de remporter la victoire sur l'ennemi - l'ennemi, c'est ici la propre femme de Pinches, Brana) ; le registre tragique enfin, quand temps mythique et temps historique s'avèrent inconciliables : c'est le cas pour Hana qui choisit d'épouser un Juif apostat de Moravie, ayant même fait de l'identité juive une identité négative ("Je ne suis pas Juif », répètet-il à l'envi, prenant à rebours la consigne donnée par Josef Šafar à sa fille : « Souvienstoi que tu es Juive ») - Hana (à présent Hanička en tchèque) quitte définitivement Polana et le monde juif traditionnel, tandis que les Juifs du village, sortis de leurs maisons, forment une haie autour d'elle et récitent le kaddish, la prière des morts. Hana ne garde de son identité juive que la tristesse inscrite dans ses yeux, signe d'un deuil interminable qui sera aussi le legs de ses enfants. Au contraire de Marijka l'infidèle, la jeune femme échappe au monde qui l'a vue naître: elle entre dans l'histoire en sacrifiant le mythe auquel est voué son peuple, l'identité collective qui était la sienne, finalement sans plus de satisfaction que Marijka restée dans son village ruthène.

\section{Conclusion}

Cette dernière histoire est le chef-d'œuvre d'Ivan Olbracht, peut-être aussi parce qu'elle touche à son intimité : c'est un lointain écho de l'histoire de sa propre mère, qui a quitté le judaïsme pour épouser le père d'olbracht ${ }^{73}$. Au terme de ce parcours, débutant avec Combat pour la culture et culminant dans les Yeux tristes, on comprend mieux en tout cas ce qui a retenu Ivan Olbracht en Ruthénie subcarpatique : en ce lieu, se croisaient toutes les questions qui lui importaient - celle du rapport entre temps personnel et temps collectif ; la part qui revient à l'identité légendaire ou mythique en chacun ; la nécessité de la justice sociale à réaliser dans le temps de l'histoire. C'est sur cette terre qu'il a enfin réussi à articuler écriture factuelle et écriture de fiction, de manière bien plus convaincante qu'à l'époque d'Anna la prolétaire ${ }^{74}$. Au lieu d'asservir la fiction à un message politique qui, en réalité, tue la fiction, il greffe la fiction sur le reportage pour explorer l'aspiration des Ruthènes à entrer dans l'Histoire et le refus des Juifs de s'y engager, en dehors de tout jugement de l'auteur. Entre légende et mythe, la fiction a recouvré ses droits, sans que soit trahi le besoin d'ancrage social si fort chez Olbracht : le reportage la légitime, en quelque sorte, puisqu'il l'a déchargée de la nécessité de se battre contre l'injustice. L'écrivain ne retrouvera jamais ailleurs qu'en Ruthénie subcarpatique l'occasion de réaliser un alliage aussi parfait.

\section{NOTES}

1. J'emprunte cette étiquette à Myriam Boucharenc: elle l'applique aux écrivains des années trente qui, dans des circonstances diverses, s'adonnent à «l'écriture seconde» du reportage. M. Boucharenc, L'écrivain-reporter au cœur des années trente, Villeneuve-d'Ascq, Presses Universitaires du Septentrion, 2004, p. 12 : «Fugitive ou durable, plus souvent expérimentale que stable, féconde à certains égards, décevante à d'autres, l'alliance de la littérature et du reportage 
reste, en raison même de ses fluctuations et de ses compromis, une réalité de l'histoire culturelle et littéraire de l'Entre-deux-guerres, assurément aussi capitale que difficile à cerner.»

2. P. Száz, dans «Ethnographic writing and the aspect of the Other in Subcarpathian works of Ivan Olbracht ", N. Zoltán et M. Roguska (éd.), Transzkulturalizmus és bilingvizmus az irodalomban [Transculturalisme et bilinguisme en littérature], Fakulta stredoeurópskych štúdií UKF v Nitre, 2018, p. 64, cite les reportages antérieurs de Vlastimil Borek (non identifiés) ou encore ceux de Vašek Káňa parus dans la revue Tvorba [Création]. Ces derniers ont ensuite été publiés sous le titre Zakarpatsko: reportáž ze života ukrajinského proletariátu v Československu [Transcarpatie: reportage sur la vie du prolétariat ukrainien en Tchécoslovaquie] aux éditions Karel Borocký à Prague en 1932, et en allemand sous le titre Karpathenland [Le pays des Carpates], aux éditions Heinrich Tejml à Prague à la même date. On peut ajouter à ces noms celui de Vojtěch Lev, dont il sera question plus bas, et celui de Jaroslav Durych, dont les reportages sont parus en 1922 dans Lidové listy [Le Quotidien populaire] et Lidové noviny [Le Journal populaire], pour être réunis en 1993 sous le titre de Duše Podkarpatské Rusi [L'Âme de la Ruthénie subcarpatique], Prague, Česká expedice (voir M. Adam, Podkarpatská Rus $v$ reportážích [La Ruthénie subcarpatique dans les reportages], 2016 [mémoire non publié], p. 20). V. Krabsová, dans Prostor Zakarpatska v české literatuře [L'espace de la Transcarpatie dans la littérature tchèque], 2012 [mémoire non publié], p. 41, signale un livre de 272 photos, dues à Bohumil Vavroušek (1875-1939), Církevní památky na Podkarpatské Rusi [Monuments religieux en Ruthénie subcarpatique], Prague, Kvasnička a Hampl, 1929. Mentionnons aussi les remarquables photos de deux autres photographes tchèques, Jaromír Funke (1896-1945) et Zdenko Feyfar (1913-2001), faites en Ruthénie dans la décennie suivante.

3. Pour les publications isolées dans la presse, voir la liste d'articles sur la Ruthénie subcarpatique, avec ou sans noms d'auteur, tirés de la presse tchécoslovaque des années 20 et 30, dans G. Brown, The Czechoslovak Orient: Carpathian Ruthenia as an imagined colonial space, Victoria University of Wellington (Nouvelle-Zélande) [thèse non publiée], 2016, p. 209-216. Pour les ouvrages scientifiques, voir le chapitre «Čeští odborníci na Podkarpatské Rusi » [«Les experts tchèques en Ruthénie subcarpatique »], dans V. Krabsová, ouvr. cité, p. 40-44.

4. Si l'on en croit le tableau proposé par V. Krabsová, ouvr. cité, p. 141-143. L'auteur ajoute à cette liste 27 autres titres d'ouvrages publiés en tchèque entre 1942 et 2001, alors que la Ruthénie a quitté la sphère tchécoslovaque depuis 1939. Le tourisme tchèque en Ruthénie est à nouveau très actif depuis les années 90 , marque de la fascination constante des Tchèques pour cette région.

5. Les trois œuvres ont été publiées par les soins de Rudolf Havel en un volume unique intitulé Zakarpatská trilogie [Trilogie transcarpatique] aux éditions Svoboda à Prague en 1972.

6. P. Száz, art. cit., p. 61-62: «[...] the three works were born, which are not only masterpieces of Czech prose of interwar period, but also a compelling and unequaled literary depiction of contemporary Verhovina, which also gave a place for these works in the cultural memory of that region. »

7. Voir les photos figurant en annexe du mémoire de N. Roshko, Obraz Podkarpatské Rusi v Olbrachtově tvorbě třicátých let [Tableau de la Ruthénie subcarpatique dans l'œuvre d'Olbracht des années 30], 2006 [mémoire non publié], p. 54-58.

8. G. Zand, « Die Karpato-Ukraine in der tschechischen Literatur 1918-1938 " [ Les Carpates ukrainiennes dans la littérature tchèque 1918-1938»], Wiener slavistisches Jahrbuch [Annales de la slavistique viennoise], vol. 48, 2002, p. 179 : «[...] ein recht inhomogenes Staatsgebilde, in dem die tschechischen Landesteile politisch, wirtschaftlich, sozial und kulturell weit überlegen waren. »

9. Ibid.

10. L'accord (dont les conditions évoquent fâcheusement l'accord conclu en septembre 1938 à Munich entre Hitler et les démocraties occidentales, qui décide du dépècement de la Tchécoslovaquie) est signé le 29 juin 1945 par le Président du gouvernement tchécoslovaque en exil en URSS, le social-démocrate Zdeněk Fierlinger, le secrétaire d'État aux Affaires étrangères tchécoslovaque Vladimír Clementis et le ministre des Affaires étrangères soviétique Viatcheslav Molotov. L'accord est entériné à Prague par l'Assemblée nationale intérimaire (non 
élue) qui vote une loi de rectification des frontières de la Tchécoslovaquie le 22 novembre 1945, puis ratifié le 6 janvier 1946 par l'Assemblée nationale constituante de la Troisième République Tchécoslovaque (1946-1948) et enfin signé par le président Edvard Beneš et son ministre des Affaires étrangères Jan Masaryk. La Ruthénie subcarpatique est intégrée à l'Union soviétique sous le nom (en tchèque) de Zakarpatská oblast Ukrajinské sovětské socialistické republiky [Oblast de Transcarpatie de la République socialiste soviétique d'Ukraine]. Voir V. Krabsová, ouvr. cité, p. 18-19. Rappelons que c'est cette frontière commune avec l'URSS qui a permis l'entrée des chars soviétiques sur le territoire tchécoslovaque en août 1968.

11. Il a existé une éphémère République houtsoule entre janvier et juin 1919, en réaction à l'envoi de troupes par la Hongrie - l'ancienne souveraine du lieu - qui tentait encore d'occuper le terrain en décembre 1918.

12. La République populaire d'Ukraine occidentale (ou République de Galicie), fondée en octobre 1918 sur les ruines de l'Autriche-Hongrie, est vaincue par les troupes polonaises en 1919. Sa voisine, la République populaire (ou nationale) ukrainienne, constituée aux dépens de l'Empire russe, est autonome, puis indépendante, entre 1917 et 1920 , date de son absorption dans l'Ukraine soviétique.

13. Voir V. Krabsová, ouvr. cité, p. 12-14. Grigorij Žatkovič fut le premier gouverneur de Ruthénie subcarpatique, mais déçu par les Tchèques qui ne tinrent pas leurs promesses d'autonomie, il démissionna de son poste en 1921 pour retourner aux États-Unis. Tomáš Garrigue Masaryk n'en est pas moins resté populaire en Ruthénie, comme en témoigne le relèvement de son monument à Užhorod en 2001, détruit lors de l'occupation hongroise en 1938.

14. Ibid., p. 15.

15. G. Zand, art. cit., p. 179.

16. I. Pop, Podkarpatská Rus [La Ruthénie subcarpatique], Prague, éditions Libri, 2005, p. 111-121.

17. Sur cette rencontre, voir G. Massino, Kafka, Löwy und das Jiddische Theater: Dieses nicht niederzudrückende Feuer des Löwy [Kafka, Löwy et le théâtre yiddish : "ce feu inextinguible de Löwy»], Frankfurt/M. Basel, Stroemfeld/Nexus, 2007 [Orig. italien : 2002]. Sur Kafka entre Juifs de l'Ouest et Juifs de l'Est, voir Delphine Bechtel, La Renaissance culturelle juive. Europe centrale et orientale, 1897-1930, Paris, Belin, p. 182-191. Sur Kafka et le yiddish, voir Marek Nekula, Franz Kafkas Sprachen [Les langues de Franz Kafka], Tübingen, Niemeyer, 2003, p. 31-39.

18. V. Lev, Brána na Východ. Karpatská Rus [Une Porte vers l'Est: la Ruthénie carpatique], Prague, Tiskový výbor československé sociálně demokratické strany dělnické, 1920, p.5-6 et p. 55 : «nešŤastnou zemi », «monstrum Evropy», «pưl Orientu a půl Ruska», «tento kout Evropy, kde se neštěstí usídlilo a zločin byl domovem ».

19. Ibid., p. 16. Ces reportages sont parus dans Právo lidu [Le Droit du peuple] en cinq livraisons en juillet et août 1920. Je traduis Východ par Est, et non par Orient, car Lev utilise par ailleurs le mot Orient : Východ désigne chez lui un monde positif, celui de la Russie révolutionnaire dont il attend beaucoup, alors qu'Orient est un terme flou et négatif sous sa plume, une réserve de vie sauvage plus que de culture.

20. G. Brown fait le relevé de ces allusions à l'Afrique dans le discours qu'on tient à l'époque sur la Ruthénie (ouvr. cité, p. 91-94).

21. Sur cette expression d'«Orient tchécoslovaque» appliquée à la Ruthénie, voir les développements de G. Brown, ibid., p. 96-103.

22. Toutes les expressions citées ici entre guillemets sont tirées de D. Bechtel et X. Galmiche, «Introduction », Cultures d'Europe Centrale, n 3 (Le Voyage dans les confins), 2003, p. 7-21.

23. G. Zand, art. cit., p. 182-183, tire cette expression de l'article «Podkarpatská Rus » [Ruthénie subcarpatique] figurant dans le $5^{\mathrm{e}}$ volume de l'encyclopédie Masarykův slovník naučný [Dictionnaire encyclopédique Masaryk], paru en 1931.

24. V. Lev, Brána na východ. Karpatská Rus, ouvr. cité, p. 56 : « Je to náše brána na Východ! ». 
25. G. Brown, ouvr. cité, p. 105 : «Rusyns complained of corruption and theft by Czech officials, particularly those working in the countryside, and Czech government reports confirmed that many officials had tried to profit from their positions ». La figure symbolique de cette exploitation éhontée de la Ruthénie est celle de František Svojše, "gendarme, journaliste et éditeur » au cœur d'un retentissant scandale médiatique à la fin des années 20 (ibid., p. 118-130).

26. G. Zand, art. cit., p. 187 : « [...] stummes Objekt der tschechischen Kolonialisierung [...]».

27. P. Száz, art. cit., cite Ivan Olbracht, p. 64: « Myšlenka jít studovat Podkarpatskou Rus ve mně vznikla $v$ dobách, kdy se v parlamentě mluvilo o tamních poměrech a o hmotné $i$ kulturní bídě... » [L'idée d'aller étudier la Ruthénie subcarpatique est née en moi à l'époque où au Parlement, on parlait de la situation qui était la sienne et de la misère matérielle et culturelle qui y régnaient].

28. I. Olbracht, "O lásce k monarchii » [«De l'amour pour la monarchie »], Bejvávalo. Sedm veselých povídek $z$ Rakouska i republiky [Le bon vieux temps. Sept histoires drôles du temps de l'Autriche et de la République], Prague, éditions Svoboda, 1950 [1927], p. 46-69. Sur les personnages de Hašek et Wittlin, voir Marie-Odile Thirouin, «Postava idiota ve středoevropském románu dvacátého století: srovnání Josefa Švejka a Piotra Niewiadomského » [«La figure de l'idiot dans le roman centre-européen du $\mathrm{xx}^{\mathrm{e}}$ siècle : une comparaison de Josef Švejk et Piotr Niewiadomski »], Česká literatura [Littérature tchèque], 2011, $\mathrm{n}^{\circ}$ 4, p. 812-827.

29. M. Adam, ouvr. cité, p. 27, et G. Brown, ouvr. cité, p. 138.

30. M. Adam, ouvr. cité, p. 25-26.

31. Pour le détail des publications d'Olbracht, voir L. Lantová, "Ivan Olbracht », Lexikon české literatury. Osobnosti, dila, instituce [Dictionnaire de la littérature tchèque: personnalités, œuvres, institutions], vol. 3/I (M-O), Prague, Academia, 2000, p. 665-671.

32. Voir J. Opelík, « Ivan Olbracht », dans J. Mukařovský (éd.), Dějiny české literatury IV. Literatura od konce 19. století do roku 1945 [Histoire de la littérature tchèque, vol. 4 : de la fin du XIXe siècle à 1945], Prague, Victoria Publishing, 1995, p. 561-562. Le roman est traduit en français par Ginette VolfPhilippot aux éditions Artia de Prague en 1962. Il a été adapté au cinéma en 1952 par Karel Steklý et à la télévision en 1980 par Antonín Dvořák.

33. Voir le texte sur le site de l'Institut de littérature tchèque de l'Académie des Sciences tchèque : <http://www.ucl.cas.cz/edicee/data/antologie/avantgarda/AVA3/2.pdf>. Le manifeste est signé par sept écrivains, par ordre alphabétique: Josef Hora, Marie Majerová, Helena Malířová (la compagne d'olbracht à l'époque), Stanislav Kostka Neumann, Ivan Olbracht, Jaroslav Seifert et Vladislav Vančura. Tous sont exclus du Parti dans le mois qui suit. Voir aussi sur le même site la réponse (non signée), publiée par Rudé pravo sous le titre : "Projev sedmi » [« Le discours des sept »].

34. J. Opelík, "Ivan Olbracht», art. cit., p.563. G. Zand parle pour sa part de "nouveau départ » (Neuanfang) et de « refuge » (Zuflucht) trouvé par Olbracht en Ruthénie (art. cit., p. 182). G. Brown (ouvr. cité, p. 132) va jusqu'à parler d' " exil qu'il s'impose à lui-même » (his self-imposed exile in Ruthenia), ce qui est sans doute excessif: Olbracht ne songe pas d'abord à s'installer en Ruthénie.

35. J. Opelík, art. cit., p. 559-564 : pour Opelík, cette deuxième phase de l'écriture d'olbracht, entre 1918 et 1929, correspond à diverses tentatives de synthèse entre écriture littéraire et écriture journalistique au service d'un projet politique ; ces deux types d'écriture étaient encore distincts et séparés dans la première phase de son œuvre (1906-1918).

36. Ces informations sont tirées de D. Beníšková, Obraz Podkarpatské Rusi v dile Ivana Olbrachta (od reportáže k románu a novele) [Le tableau de la Ruthénie subcarpatique dans l'œuvre d'Ivan Olbracht (du reportage au roman et à la nouvelle)], 2011 [mémoire non publié], p. 11.

37. Sa langue de communication avec la population locale est principalement le tchèque, mais sa connaissance des langues slaves lui permet d'entrer dans la langue des Ruthènes, comme sa connaissance de l'allemand l'aide à comprendre le yiddish : ses reportages sont parsemés de citations en langue originale. 
38. Ivan Olbracht, «Země starosti » [«Une terre objet d'inquiétude »], České slovo [La Parole tchèque], 17 mars 1935, p. 3 (cité par N. Roshko, ouvr. cité, p. 49) : «Přišel jsem sem psáti beletrii. Ale když jsem viděl, do jak bezměrné bídy byla celá země vehnána, jaké kulturní a politické zmatky se tu vědomě a za zištnými účely vyvolávají a jak nebezpečná a dobřre organizovaná smečka lotrů rabuje celé kraje, nebylo možno alespoň v první době nenechati beletrii beletrií a nepsati o nich. Mé ćlánky vzbudily hodně vzruchu. A v něm bylo hlavní otázkou, co vím a co nevím. Věděl jsem hodně, ale napsal jen zlomek toho, poněvadž pravda sice zůstává pravdou, ale aby se stala pravdou oficiální, $k$ tomu je třeba důkazů jednotlivci často nedostupných. A právě zapomenutý kraj, v němž jsem meškal, byl pravým eldorádem panských hrabivců. Zde se kradlo a lumpačilo v božském klidu a samozřejmě. Tady byla pravá loupežnická idyla. A sem přišlo individuum, aby ji rušilo. » (je traduis)

39. P. Száz, art. cit., p.64-69. J'emprunte ici à P. Száz le raisonnement et les catégories qu'il développe dans une version plus longue du même article, accessible en ligne: <https:// www.academia.edu/35117076/Ethnographic_

writing_and_the_aspect_of_the_Other_in_Subcarpathian_works_of_Ivan_Olbracht> （p.11-18 dans cette version de 33 pages).

40. Literární noviny est une publication culturelle fondée en 1927 aux éditions Pokrok [Progrès], dans le but d'intéresser le plus large public possible aux questions littéraires. Ce journal a connu deux périodes de publication, 1927-1941 et 1946-1951. En 1930/31, il en est à sa $5^{\mathrm{e}}$ année de parution et passe aux éditions Sfinx, sous la direction de Josef Hora - l'ami d'olbracht - qui collaborait déjà au journal. Literární noviny paraît dès lors avec le sous-titre Kulturní zpravodaj moderního člověka [Courrier culturel de l'homme moderne] et traite de sujets plus largement culturels. 21 numéros paraissent entre décembre 1930 et décembre 1931, sur un rythme quasiment bimensuel. Voir Z. Trochová, "Literární noviny», Lexikon české literatury. Osobnosti, dila, instituce, ouvr. cité, vol. 2/II (K-L), Prague, Academia, 1993, p. 1204.

41. A. Londres, Le Juif errant est arrivé, Paris, Albin Michel, 1930 [Věčný žid před cílem, trad.H. Teigeová, Prague, Václav Petr, 1931]; M. Bártha, Kazár földön [Le pays des Khazars], Kolozsvär, Ellenzek, 1901 [V zemi Chazarů, trad. J. D. Matyáš, Mukačevo (édition à compte d'auteur), 1927]. Pour Olbracht (Hory a staletí, Prague, Melantrich, 1935, p. 50-51), Albert Londres, venu en Ruthénie en 1929, n'a pas su voir que la misère juive était celle de toutes les Carpates ; quant à l'usure juive, écrit-il, elle a pratiquement disparu depuis l'époque où Bártha fréquentait le pays, pour être remplacée par une forme d'usure bien plus inhumaine selon lui, celle pratiquée par les banques tchécoslovaques.

42. Pour le détail des réactions à la publication des reportages d'Olbracht, voir G. Brown, ouvr. cité, p. 131-146, en particulier le discours au Parlement du député communiste Josef Štětka en 1932 (p.134), la création consécutive d'un Comité de secours ouvrier pour venir en aide aux victimes de la faim en Ruthénie subcarpatique [Komitét dělnické pomoci pro zachránu hladovějicích $v$ Podkarpatské Rusi] (p. 136) et le séjour de Stanislav Kostka Neumann en Ruthénie sur les traces de son ami Olbracht en 1932 et 1933 (p. 147-149) - encore plus critique qu'Olbracht, Neumann en rapporte des reportages et un journal de voyage publiés en feuilleton dans Lidové noviny [Le Journal populaire], puis en livre sous le titre Enciány z Popa Ivana [Gentianes rapportées du mont Pop Ivan], Brno, Polygrafie, 1933 (voir Š. Mařanová, Dvojí obraz 'země beze jména'. Podkarpatská Rus v meziválečné české beletrii a publicistice [L'image double d'une "terre sans nom». La Ruthénie subcarpatique dans la littérature et la presse tchèques de l'entre-deux-guerres], 2007 [mémoire non publié], p. 58-64) et Československá cesta [Un voyage tchécoslovaque], Prague, František Borový, 1934 (voir M. Adam, ouvr. cité, p.41-54). Dans un registre moins polémique, Marie Majerová (elle appartient elle aussi au cercle des écrivains engagés autour d'olbracht) consacre un essai à la Ruthénie dans son livre destiné à la jeunesse, Výlet do Československa [Excursion en Tchécoslovaquie], Prague, Melantrich, 1937 : G. Brown (ouvr. cité, p. 149) attire l'attention sur la couverture de ce livre, une photo d'enfants ruthènes en costume folklorique censés représenter à eux seuls toute la Tchécoslovaquie, à une date cruciale pour le pays déjà sous la menace nationale-socialiste. 
43. Pál Száz, art. cit., p. 17 de la version longue.

44. Olbracht se désigne lui-même comme "témoin, certes de parti pris » [svědek, pravda, hodně zaujatý] et "auteur épris de ses personnages » [autor zamylovan do svých postav] (Hory a staletí, ouvr. cité, p. 119 et p. 130).

45. D. Beníšková, ouvr. cité, p. 13, et M. Adam, ouvr. cité, p. 29.

46. I. Olbracht, «Boj o kulturu na Podkarpatské Rusi», Literární noviny, 5ªnnée, $\mathrm{n}^{\circ} 16$ (septembre 1931), p. 5 [partie I]; $\mathrm{n}^{\circ} 18$ (octobre 1931), p. 3-4 [parties II et III]; $\mathrm{n}^{\circ} 19$ (novembre 1931), p. 4 [parties IV et V] ; $\mathrm{n}^{\circ} 20$ (novembre 1931), p. 3-4 [parties VI et VII]. Les articles sont illustrés de photos en noir et blanc. Le numéro 17 de Literární noviny (octobre 1931) ne publie pas la suite du reportage commencé avec le numéro 16, sans doute à cause de la mort du père d'Olbracht, l'écrivain Antal Stašek décédé à Prague le 9 octobre 1931, largement commentée dans ce numéro aux pages 1-2.

47. I. Olbracht, Země bez jména. Reportáže z Podkarpatska, Prague, Otto Girgal, 1932, 92 pages.

48. I. Olbracht, Hory a staletí. Kniha reportáží z Podkarpatska, Prague, Melantrich, 1935, 240 pages. Melantrich est une maison d'édition fondée à Prague en 1898 par le Parti social-national tchèque, un parti socialiste et nationaliste qui après 1918, prend le nom de Parti socialiste tchèque (tchécoslovaque à partir de 1919), puis de Parti socialiste-national tchécoslovaque de 1926 à 1948 (le journal du Parti, pendant cette période, est le České slovo [La Parole tchèque] où Olbracht publie dans les années 30). Pendant l'entre-deux-guerres, Melantrich, maison bien supérieure en taille et en moyens à celle d'Otto Girgal, «s'est fait une spécialité de l'édition des œuvres marquantes des romanciers et poètes tchèques » : elle assurait sans doute une meilleure diffusion au livre d'Ivan Olbracht. Voir O. Homola et A. Zach, «Melantrich », Lexikon české literatury. Osobnosti, díla, instituce, vol. 3/I (M-O), ouvr. cité, p. 203-211.

49. Les articles sont signés Ivan Olbracht et datés de «Volové, août 1931 » [V Volovém, v srpnu 1931] en tête de la première livraison et à la fin de la dernière.

50. I. Olbracht, Země bez jména, ouvr. cité, p. 73 : « Ta země jest ještě bez jména. Či, lépe řečeno, má jich přiliš, aby je mohla míti.».

51. Olbracht énumère ces différents noms qu'il donne en tchèque (ibid.): Ruská krajina, Podkarpatská Rus, Zakarpatská Rus, Zakarpatská Ukrajina, Zakarpatsko, Podkarpatsko.

52. Ibid., p. 73-74 : «Ale ani tři slovanské kmeny, které zde žijí, [...] nemají ještě jednotného národního jména. [...] Národ si může dáti jméno jen sám. Podkarpatský lid národem ještě není. Jen etnografickou masou. »

53. Les deux épigraphes choisies - un extrait d'une chanson populaire ruthène et un extrait d'un récit de berger - prennent néanmoins en charge la dimension polémique enlevée du titre et préviennent : ce pays est un pays qui fait face à une agression, mais qui est apte à se défendre, car « les armes sont prêtes » (zbraně byly připraveny).

54. F. X. Šalda, «Česká kolonizace na Podkarpatské Rusi » [« La colonisation tchèque en Russie subcarpatique »], Šaldův zápisník IV [ Les Carnets de F.X. Šalda], Prague, Otto Girgal, 4 e année (1931-32), p. 315 (cité par V. Krabsová, ouvr. cité, p. 50) : « Nemáme zámořských kolonií [...]. Ale za to máme Podkarpatskou Rus, jakýsi mlhavý východní př́věsek republiky za Slovenskem, o niž neměl před válkou nikdo určitější představy. A tato zemička, obydlená ubohým rusínským lidem, stala se po světové válce první zkouškou kolonizačních schopností českého měšráka. Dopadlo to však žalostně. Před válkou kolonisovali MaĎaři na Podkarpatské Rusi a kolonisovali, jak ukazuje Ivan Olbracht, i lidštěji, $i$ rozumněji a důmyslněji. Česká kolonisace dopadla $v$ tradici kolonisací všech velkých kulturních národů západoevropských; došlo se tam $k$ tomu, že konec koncủ nejbezpečnější kulturní nástroj je četnická puška. » (je traduis)

55. Olbracht (Hory a staletí, ouvr. cité, p.122) applique encore à ce pays une expression significative, celle de «terre des nombreux siècles » (země mnoha stoletî).

56. Voici les titres tchèques des 10 chapitres de 1935 : «Vesnice jedenáctého století », "Ti, o kterých tu dříve nebylo slýcháno », "Židé », "Země bez jména », "Loupežníci », "Století 
osmnácté », « Obtížné jednání s Anćou Burkalovou », « Mandra », « O zuřivosti chtění », « Země se nacionalisuje ».

57. Parmi les «produits d'importation» tchèques, Olbracht range l'antisémitisme : contrairement à Vojtěch Lev qui considère les Juifs comme partiellement responsables des malheurs de la Ruthénie, juste derrière les Hongrois, Olbracht pense que Ruthènes et Juifs sont solidaires dans leur misère commune, quoique vivant séparément. Mais il signale l'absence de rumeurs de meurtres rituels et de pogromes dans ce pays. Il s'en prend finalement moins à l'usure juive, presque disparue et de toute façon bien régulée, qu'à l'emprise des "rabbis " hassidiques sur une population juive miséreuse qu'ils s'entendent à exploiter aussi au profit des nouveaux maîtres tchèques (Hory a staletí, ouvr. cité, p. 68-70).

58. O.Zitová, dans Thomas Mann und Ivan Olbracht. Der Einfluss von Manns Mythoskonzeption auf die karpatoukrainische Prosa des tschechischen Schriftstellers [Thomas Mann et Ivan Olbracht. L'influence de la conception du mythe chez Mann sur les textes de l'écrivain tchèque consacrés aux Carpates ukrainiennes], Stuttgart, ibidem-Verlag, 2014, p. 63-64, repère dans les reportages «l'amorce de certains passages du roman » de Nikola Šuhaj (Ansätze zu einigen Passagen des Romans) : elle donne l'exemple de la métaphore initiale centrale, par laquelle le paysage, dans le reportage de 1932, est assimilé à "une boule de papier froissée " (kus zmačkaného papíru), métaphore développée et amplifiée au tout début du roman.

59. Les informations sur ce film sont tirées de V. Krabsová, ouvr. cité, p. 77-78, et de Š. Mařanová, ouvr. cité, p. 39-44. Le film, dont la musique est due au compositeur tchèque Bohuslav Martinů (sa collaboration, comme celle de Vančura, sont un indice de l'écho important rencontré par les reportages d'olbracht dans la société tchèque), est visible en deux parties sur une chaîne YouTube ukrainienne: <https://www.youtube.com/watch?v=zTRrpPN7U2g> et <https:// www.youtube.com/watch?v=YdYzGPNI3D4> [consulté le 13 mai 2020].

60. I. Olbracht, Nikola Šuhaj loupežník: román, Prague, éditions Sfinx, 1933 [Nikola Suhaj le brigand, trad. de Jean et Jirina Danès, Gallimard, 1933]. Le roman a donné lieu à trois adaptations filmiques en 1947 (Nikola Šuhaj par Miroslav Josef Krňanský), 1977 (Nikola Šuhaj loupežník par Evžen Sokolovský) et 1978 (Ballada pro banditu [Ballade pour un bandit], comédie musicale d'après la pièce de Milan Uhde et Miloš Štědroň, filmée par Vladimír Sís). Dans Hory a staletí, ouvr. cité, p. 91, Olbracht fait remarquer qu'en ukrainien, on appelle opryšky les vengeurs et agents de la justice sociale, distincts des bandits ordinaires (lupiči), tandis que le tchèque fait mal la différence entre lupiči et loupežníci (de loupit, voler, apparenté à loupat, peler, décortiquer).

61. On remarquera que le nom du personnage principal du roman est légèrement différent $d u$ nom du personnage historique, comme pour marquer l'écart existant entre la fiction et l'histoire. Voir M. Pohorský, "Čas mýtu - Nikola Šuhaj loupežník» [«Le temps du mythe - Nikola Šuhaj loupežník »], Česká literatura [Littérature tchèque], vol. 19, n 1/2 (1971), p. 120-131.

62. V. Krabsová, ouvr. cité, p. 94, cite un article d'olbracht paru le 18 août 1932 dans České slovo, soit un an avant la publication de son roman sur Šuhaj : «V roce 1920 a 1921 na Vrchovině vystoupil loupežnik Nikola Šuhaj. Podle našich predstav byl to zcela obyčejný loupežník, ale ne tak ve fantazii podkarpatoruského lidu. Při loňském zájezdu na Podkarpatskou Rus zastihl jsem postavu Šuhajovu ve stavu tvořicí se legendy, tvořicí se, to je zajímavé. Legendární prvky, tj. prvek macbethovský a samsonovský, se mísí se skutečností. A o tom piši román. » [En 1920 et 1921, le brigand Nikola Šuhaj a fait parler de lui dans la Verchovina. Selon nos représentations habituelles, c'était un brigand tout à fait ordinaire, mais ce n'est pas ce qu'y voit l'imagination du peuple ruthène. L'an passé, lors de mon voyage en Ruthénie subcarpatique, j'ai trouvé le personnage de Šuhaj pris dans une légende en train de se constituer, vraiment de se constituer, c'est très intéressant. Des éléments légendaires, du style de Macbeth ou de Samson, se mêlent à la réalité. Et c'est là-dessus que j'écris un roman.]

63. A. Jolles, Formes simples, Paris, Éditions du Seuil, 1972 [1930], p. 27-54.

64. Voir le détail de ces réactions, connues sous le nom de "campagne anti-Šuhaj», dans N. Roskho, ouvr. cité, p. 36-42, et O. Zitová, Thomas Mann und Ivan Olbracht, ouvr. cité, p. 64-67. 
65. I. Olbracht, Hory a staletí, ouvr. cité, p. 111.

66. Ibid., p. 120 : « Nikola Šuhaj velkým loupežníkem ve smyslu sociálním nebo politickým nebyl. Ale splnil jiné poslání loupežniků, poslání věru nejkrásnější, a v tom se přibližuje loupežníkům největším, ba samému Oleksovi Dovbošovi: oplodnil lidovou fantasii. / Teprve duše rusínského lidu, toužící po svém právu a své spravedlnosti, učinila $z$ Nikoly Šuhaje velkého loupežnika a postavu tragickou, obdařivši ho vší silou a mocí, kterých sama nemá a po nichž tak horoucně touží. » (je traduis)

67. A. Jolles, Formes simples, ouvr. cité, p. 77-101.

68. T. Mann, Die Geschichten Jaakobs [Les Histoires de Jacob], Berlin, Fischer Verlag, 1933 ; Der junge Joseph [Le jeune Joseph], Berlin, Fischer Verlag, 1934 ; Joseph in Ägypten [Joseph en Égypte], Vienne, Verlag Bermann-Fischer, 1936 (le quatrième volume, Joseph der Ernährer [Joseph le nourricier], paraît à Stockholm en 1943). La traduction tchèque d'olbracht, Josef a bratři jeho, paraît sous le titre de Př́běhy Jákobovy, Mladý Josef, Josef v Egyptě chez Melantrich à Prague, en 1934 pour les deux premiers volumes (la compagne d'olbracht à l'époque, Helena Malířová, participe à leur traduction) et en 1937 pour le troisième. Quant au quatrième volume, Josef Živitel, il paraît en 1951 chez Melantrich, mais dans la traduction de Pavel Eisner. Signalons toutefois qu'en 1939, Olbracht poursuit ce «filon » biblique, dont on voit l'importance pour lui, en rédigeant pour les enfants des Récits bibliques: l'Ancien Testament pour la jeunesse (Biblické př̉běhy: Starý zákon pro mládež), publiés en 1939 chez Melantrich à Prague : ce sont en quelque sorte des anti-reportages consacrés exclusivement au temps mythique, tandis que l'Histoire bascule dans la guerre et le chaos.

69. O. Zitová, ouvr. cité, p. 32-42.

70. I. Olbracht, Golet v údolí, Prague, Melantrich, 1937 [Le Golet dans la vallée, trad. par Ginette VolfPhilippot, Prague, Artia, 1964]. Il aura fallu attendre 1995 pour une première adaptation cinématographique sous la direction de Zeno Dostál.

71. O. Zitová, ouvr. cité, p. 87-88. Je modifie la traduction française des titres des trois nouvelles que propose G. Volf-Philippot : «Zázrak s Julčou », « Událost v mikve », « O smutných očích Hany Karadžičové ».

72. Selon O. Zitová, ouvr. cité, p. 89, le critique Václav Černý identifie trois registres différents, affectés successivement à chacune des trois nouvelles : comique, tragi-comique, tragique.

73. Ibid., p. 51. Voir aussi M. Plachta, « Antal Stašek (JUDr. Antonín Zeman) 1843-1931 », Semilské noviny, $17^{\mathrm{e}}$ année, $\mathrm{n}^{\circ} 3$, 31 mars 2009, p. 13. De son vrai nom, Ivan Olbracht s'appelait Kamil Zeman. À l'exemple de son père, l'écrivain Antal Stašek (Antonín Zeman), il s'est doté d'un nom de plume. Sa mère, Kamila Schönfeldová, appartenait à la bourgeoisie juive assimilée (de langue allemande) de la ville natale d'olbracht, Semily au nord-est de la Bohême, une région où, avant la guerre, vivaient de nombreux Allemands, ce qui explique aussi l'excellente connaissance qu'Olbracht avait de cette langue.

74. On peut regretter que tout ce pan de l'œuvre d'olbracht ne soit pas véritablement accessible en français. Il paie là sans doute son allégeance à Gottwald à la fin de la guerre et sa réintégration dans le Parti communiste tchécoslovaque qui l'ont compromis avec la terreur stalinienne. Il est en effet décédé en 1952, quelques jours après Rudolf Slánský, principale victime d'un procèsspectacle dont Olbracht a eu le temps d'approuver l'issue dans la presse, semble-t-il (J. Gerber, Ein Prozess in Prag: Das Volk gegen Slánský und Genossen [Un procès à Prague : le peuple contre Slánský et ses camarades], Göttingen, Vandenhoeck \& Ruprecht, 2016, p. 227). Ses reportages ruthènes venaient certes d'être publiés en allemand à Berlin-Est (Berge und Jahrhunderte [Les Montagnes et les siècles], trad. Elisabeth Borchardt, Berlin-Est, Rütten \& Loening, 1952), mais dans une version réduite et expurgée de tous les passages sur le sionisme et sur le nationalisme ukrainien dont olbracht affirmait en 1935 que c'est lui qui l'emporterait un jour en Ruthénie. Ces coupes sont-elles dues au traducteur, à l'éditeur ou à l'auteur lui-même? C'est difficile à dire. Assorties de quelques ajouts en langue de bois, elles donnent en tout cas un caractère schématique et dogmatique à ces 
textes en allemand qui n'ont donc pas été traduits en français. Quant aux " romans ruthènes ", les traductions en sont malheureusement anciennes et confidentielles.

\section{RÉSUMÉS}

Cet article expose les circonstances dans lesquelles l'écrivain Ivan Olbracht a été amené à séjourner dans "l'Orient tchécoslovaque " et s'en est fait le défenseur sur la scène politique pragoise. Sont examinées les trois éditions qu'ont connues ses reportages, pour saisir le positionnement et la stratégie d'écriture choisis par Olbracht. Enfin, l'attention se porte sur le rapport qui se tisse entre ces reportages et les textes de fiction qu'il écrit parallèlement en Ruthénie : il les consacre à ceux de ses habitants qui cherchent à entrer dans l'histoire et à ceux qui refusent au contraire de s'y engager - les Ruthènes avec leur légende ; les Juifs hassidiques avec leur mythe. La combinaison des écritures factuelle et fictive donne ainsi à olbracht la possibilité d'explorer l'agencement mystérieux, et propre à ce pays, des différentes temporalités individuelles et collectives.

This article explores the circumstances under which writer Ivan Olbracht was led to sojourn in "the Czechoslovakian Orient" and stood for it on the Prague political scene. The article compares the three existing editions of Olbracht's reports, in order to understand the position and the writing strategy he has chosen. Last of all, the article focuses on the relationship between these reports and the fictional texts that Olbracht has written at the same time in Ruthenia. These works of fiction are centered on those inhabitants of Ruthenia who are trying to enter History, and those who, on the contrary, refuse to engage in it: the Ruthenians and their legend, on the one hand, and the Hasidic Jews and their myth, on the other hand. This combination of factual and fictional writings enables olbracht to explore the mysterious layout of both individual and collective temporalities, which are so peculiar to this country.

\section{INDEX}

Mots-clés : littérature tchèque, reportage, fiction

Keywords : Czech literature, reports, fiction

\section{AUTEUR}

\section{MARIE-ODILE THIROUIN}

Université de Lyon

Marie-Odile Thirouin, maître de conférences à l'Université de Lyon, enseigne la littérature comparée et travaille essentiellement sur l'Europe centrale du premier $\mathrm{xx}^{\mathrm{e}}$ siècle, les transferts culturels en Europe et les écritures juives. 